\title{
PERAN SELF EFFICACY SEBAGAI MEDIATOR ANTARA JOB RESOURCES DAN WORK ENGAGEMENT PADA DOKTER HEWAN
}

\author{
Puspa P. Sajuthi ${ }^{1}$, Raja O. Tumanggor ${ }^{2}$, P. Tommy Y. S. Suyasa ${ }^{3}$ \\ ${ }^{1}$ Program Studi Magister Psikologi Profesi, Universitas Tarumanagara, Jakarta \\ Email: puspa.sajuthi@gmail.com \\ ${ }^{2}$ Fakultas Psikologi, Universitas Tarumanagara, Jakarta \\ Email: sumatera.suyasa@gmail.com \\ ${ }^{3}$ Fakultas Psikologi, Universitas Tarumanagara, Jakarta \\ Email: lusoloania@gmail.com
}

Masuk : 15-04-2020, revisi: 25-10-2020, diterima untuk diterbitkan : 31-10-2020

\begin{abstract}
This study explores the role of self-efficacy as a mediator between job resources and work engagement among veterinarians. Self-efficacy is seen as the degree of confidence of the veterinarian in performing their duties. Job resources is an aspect of work that individuals can use to handle the demands and challenges of their work. Job resources in this study includes opportunities for professional development and skills discretion. Opportunties for professional development refers to the opportunities provided for veterinarians to enroll in courses that can develop their veterinary knowledge. Skills discretion refers to the extent to which veterinarians acquire the opportunity to apply all their skills, both as a veterinarian and other skills such as negotiation and creativity. Participants included 32 veterinarians from $X$ Veterinary Clinic, Jakarta. The analysis methods used were regression and bootstrapping. The results showed that self-efficacy is proven to act as a partial mediator in explaining the relationship between skills discretion and work engagement.
\end{abstract}

Keywords: work engagement, veterinarian, self efficacy, opportunities for professional development, skills discretion

\begin{abstract}
ABSTRAK
Penelitian ini mengeksplorasi peran self efficacy sebagai mediator antara job resources dan work engagement pada dokter hewan. Self efficacy digambarkan sebagai derajat keyakinan dokter hewan dalam melakukan pekerjaannya. Job resources merupakan aspek pekerjaan yang dapat digunakan individu untuk menangani tuntutan dan tantangan pekerjaannya. Job resources pada penelitian ini digambarkan dengan opportunities for professional development dan skills discretion. Opportunties for professional development mengacu pada kesempatan yang diberikan bagi para dokter hewan untuk mengikuti kursus yang dapat mengembangkan ilmunya sebagai dokter hewan. Skills discretion mengacu pada sejauh mana dokter hewan memeroleh kesempatan untuk menerapkan segenap keterampilan yang dimilikinya baik keterampilan sebagai dokter hewan maupun keterampilan lainnya seperti negosiasi dan berkreasi. Partisipan adalah 32 orang dokter hewan di Klinik Hewan X, Jakarta. Metode analisis yang digunakan adalah regresi dan bootstrapping. Hasil penelitian menunjukkan bahwa self efficacy teruji berperan sebagai mediator parsial dalam menjelaskan hubungan antara skills discretion dan work engagement.
\end{abstract}

Kata Kunci: work engagement, dokter hewan, self efficacy, opportunities for professional development, skills discretion

\section{PENDAHULUAN}

Profesi dokter hewan praktisi hewan kecil merupakan salah satu profesi yang sedang mengalami perkembangan di Indonesia. Perkembangan profesi ini didorong oleh peningkatan minat masyarakat terhadap hewan kesayangan atau hewan peliharaan seperti anjing dan kucing (Franedya, 2009). Hewan peliharaan ini sudah dianggap sebagai bagian dari keluarga (Sukarelawati, 2017) sehingga kehadiran dokter hewan praktisi hewan kecil sangat penting untuk memenuhi kebutuhan masyarakat ini.

Ada sejumlah tantangan yang harus dihadapi oleh dokter hewan praktisi hewan kecil. Pertama, kurikulum kedokteran hewan di Indonesia masih berfokus pada penanganan hewan ternak sehingga dokter hewan praktisi hewan kecil kurang memeroleh perbekalan yang cukup selama 
perkuliahan (Surjanata et al., 2010). Kedua adalah tuntutan klien yang tinggi, hal ini disebabkan karena mayoritas pemilik hewan peliharaan adalah mereka yang berasal dari kondisi sosial ekonomi menengah ke atas (Kartini \& Komariyah, personal communication, 2018). Tantangan lain yang harus dihadapi adalah jam kerja yang panjang, risiko terluka pada saat memeriksa hewan, dan paparan terhadap zoonosis atau penularan penyakit melalui hewan.

Kondisi dokter hewan yang harus menghadapi tantangan-tantangan tersebut mencerminkan pentingnya bagi profesi ini untuk memiliki mental kerja yang positif. Dalam psikologi industri/organisasi, mental kerja yang positif ini disebut sebagai work engagement. Work engagement didefinisikan sebagai a positive, fulfilling work-related state of mind that is characterized by vigor, dedication, and absorption (Schaufeli, Bakker, \& Salanova, 2006). Vigor berarti energi, semangat, dan keinginan individu untuk pergi bekerja dan menghadapi tekanan dalam pekerjannya. Dedication menggambarkan individu yang memiliki antusiasme, inspirasi, dan kebanggaan terhadap pekerjaannya. Absorption didefinisikan sebagai perasaan senang yang dirasakan individu saat ia terlarut dalam pekerjaannya dan lupa waktu saat bekerja (Schaufeli et al., 2006).

Vigor dibutuhkan oleh dokter hewan karena mereka memiliki jam kerja yang panjang atau bisa mencapai 12 jam per harinya sehingga mereka perlu memiliki energi dan semangat dalam bekerja. Dedication dibutuhkan oleh dokter hewan karena mereka perlu memiliki antusiasme dalam belajar sehingga mereka dapat mengembangkan profesi mereka sebagai dokter hewan. Absorption dibutuhkan oleh dokter hewan karena mereka perlu fokus dalam memeriksa hewan agar dapat menentukan diagnosa yang tepat.

Work engagement menjadi suatu faktor yang penting untuk dimiliki oleh dokter hewan. Work engagement memiliki korelasi yang tinggi dengan job performance atau performa kerja (Bakker, 2011; Bakker, Demerouti, \& Verbeke, 2004; Byrne, Peters, Weston, 2016). Dengan demikian, penting bagi dokter hewan untuk memiliki work engagement yang tinggi dengan harapan performa kerja mereka juga akan mengalami peningkatan.

Secara umum, ada dua buah faktor yang berperan dalam meningkatkan work engagement. Faktor pertama adalah job resources yang didefinisikan sebagai aspek dari pekerjaan yang dapat mengurangi tuntutan pekerjaan, membantu mencapai tujuan bekerja, menstimulasi pertumbuhan karyawan (Schaufeli \& Bakker, 2004). Job resources terdiri dari perfomance feedback, support from colleagues, supervisory coaching (Schaufeli \& Bakker, 2004), autonomy, opportunities for professional development (Xanthopoulou, Bakker, Demerouti, \& Schaufeli, 2009) dan skills discretion (Viotti \& Converso, 2016). Faktor kedua adalah personal resources merupakan evaluasi individu terhadap dirinya sendiri yang bersifat positif (Hobfoll, Johnson, Ennis, \& Jackson, dalam Bakker, 2011). Personal resources terdiri dari self efficacy, self esteem, optimism (Lorente, Salanova, Martinez, \& Vera, 2014).

Job resources dikatakan memiliki peran besar terhadap peningkatan work engagement (Bakker, 2011; Christian, Garza, \& Slaughter, 2011; Schaufeli \& Bakker, 2004). Di sisi lain, ada penelitian yang menemukan bahwa job resources tidak memiliki korelasi dengan work engagement (Ayu, Maarif, \& Sukmawati, 2015). Dengan demikian masih terdapat inkonsistensi hubungan job resources dengan work engagement sehingga perlu dilakukan penelitian ulang, khususnya dalam konteks budaya yang berbeda. 
Penelitian mengenai work engagement pada dokter hewan sebelumnya diteliti di Belanda (Mastenbroek, Jaarsma, Demerouti, Muijtjens, Scherpbier, \& Van Beukelen, 2013a). Dalam penelitian ini disebutkan bahwa job resources berupa opportunities for professional development dan skills discretion berperan besar terhadap peningkatan work engagement dokter hewan. Penelitian Mastenbroek et al (2013a) juga menemukan bahwa personal resources berupa self efficacy berkorelasi terhadap work engagement dokter hewan. Penelitian lain menyebutkan bahwa self efficacy berperan sebagai mediator parsial antara job resources dan work engagement (Mastenbroek, Jaarsma, Scherpbier, van Beukelen, \& Demerouti, 2012). Peran self efficacy sebagai mediator parsial antara job resources dan work engagement juga didukung oleh penelitian yang dilakukan oleh Xanthopoulou, Bakker, Demerouti, dan Schaufeli (2007).

Keterbatasan dari penelitian Mastenbroek et al (2013a) adalah alat ukur self efficacy yang digunakan dalam penelitiannya dinilai penulis kurang spesifik terhadap pekerjaan. Di sisi lain Bandura (1997) mengatakan bahwa dalam mengukur self efficacy penting untuk memasukkan konteks pekerjaan. Dengan demikian, diperlukan pembuatan alat ukur self efficacy yang dimasukkan unsur konteks pekerjaan.

Berdasarkan penjelasan sebelumnya, peneliti tertarik untuk meneliti peran self efficacy sebagai mediator antara job resources dan work engagement. Namun peneliti tertarik untuk menggunakan elemen job resources berupa opportunities for professional development dan skills discretion. Alasan peneliti memilih kedua elemen job resources ini adalah karena keduanya telah terbukti berperan dalam memprediksi work engagment pada konteks penelitian dokter hewan (Mastenbroek et al., 2013a). Maka, peneliti mengajukan dua buah hipotesis yang akan diuraikan pada paragraf berikutnya.

Hipotesis pertama berbunyi self efficacy berperan sebagai mediator antara opportunities for professional development dan work engagement. Dengan demikian, self efficacy diduga dapat memediasi hubungan antara opportunities for professional development dan work engagement. Contoh konkritnya adalah dokter hewan yang banyak mendapat pelatihan pengembangan profesi akan mengalami peningkatan self efficacy dan pada akhirnya meningkatkan work engagement yang dimilikinya.

Hipotesis kedua berbunyi self efficacy berperan sebagai mediator antara skills discretion dan work engagement. Dengan demikian, self efficacy diduga dapat memediasi hubungan antara skills discretion dan work engagement. Contoh konkritnya adalah dokter hewan yang mendapatkan kesempatan untuk mempraktikkan keterampilannya akan mengalami peningkatan self efficacy dan pada akhirnya meningkatkan work engagement yang dimilikinya.

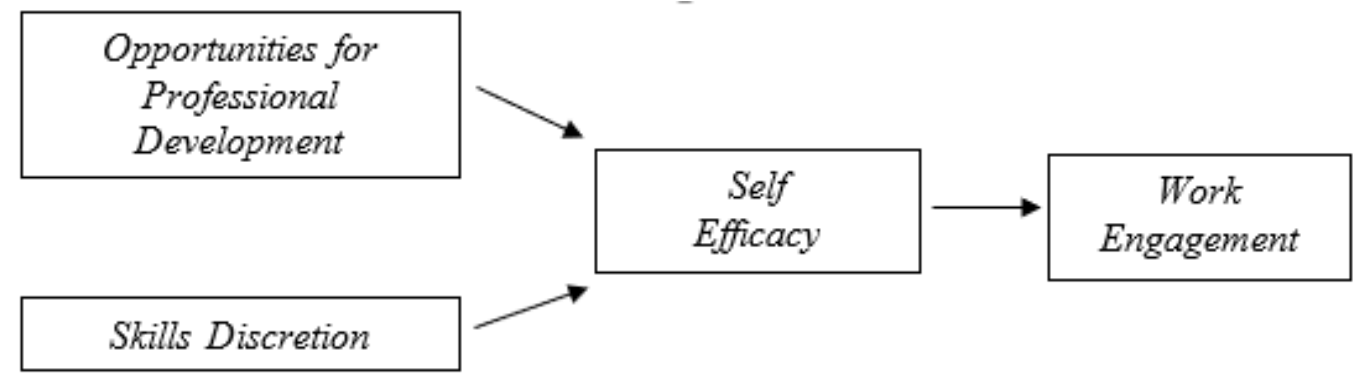

Gambar 1. Kerangka berpikir 


\section{METODE PENELITIAN}

Penelitian ini melibatkan 32 orang responden dokter hewan yang bekerja di klinik hewan X. 22 orang berjenis kelamin perempuan $(68.75 \%)$. Usia partisipan berkisar dari 25 hingga 70 tahun $(M=36 ; S D=11)$. Lama bekerja di klinik hewan X berkisar dari 1 hingga 35 tahun $(M=10 ; S D$ =9). Peneliti memilih klinik X karena klinik $X$ merupakan salah satu klinik hewan tertua di Indonesia serta merupakan salah satu pelopor klinik hewan di Indonesia. Selain itu, klinik X juga merupakan klinik dengan jumlah dokter hewan terbanyak di satu tempat.

Ada empat buah alat ukur yang digunakan untuk mengukur setiap variabel dalam penelitian ini. Keempat variabel tersebut adalah (i) work engagement, (ii) opportunities for professional development, (iii) skills discretion, (iv) self efficacy. Setiap alat ukur ditulis dalam bahasa Indonesia, menggunakan skala Likert, dan memiliki empat pilihan jawaban.

Alat ukur yang digunakan untuk mengukur work engagement adalah Ultrecht Work Engagement Scale (UWES) yang dikembangkan oleh Schaufeli et al., (2006). Selanjutnya alat ukur ini diadaptasi ke dalam bahasa Indonesia agar dapat dipahami oleh partisipan yang seluruhnya berkewarganegaraan Indonesia. Alat ukur ini terdiri dari 17 butir soal yang kemudian menjadi 12 butir soal karena ada 5 butir soal yang dieliminasi. Kelima butir soal yang dieliminasi ini memiliki nilai outer loading di bawah 0.6 yang berarti butir-butir soal tersebut kurang berfungsi baik dalam mengukur work engagement. Contoh butir alat ukur ini adalah 'saya merasa bersemangat ketika bekerja.', 'saya merasa bangga dengan pekerjaan yang saya lakukan', dan 'saya begitu konsentrasi dengan pekerjaan saya'. Reliabilitas diukur dengan menggunakan Alpha's Cronbach dan diperoleh nilai 0.871, artinya alat ukur work engagement ini tergolong reliabel.

Alat ukur yang digunakan untuk mengukur opportunities for professional development adalah VET-DRQ pada sub bagian opportunities for professional development yang dikembangkan oleh Mastenbroek, Demerouti, van Beukelen, Muijtjens, Scherpbier, dan Jaarsma (2013b). Alat ukur ini diadaptasi ke dalam bahasa Indonesia dan ditambahkan beberapa butir soal. Hasilnya terdapat 8 butir soal dengan nilai outer loading di atas 0.6. Hal ini berarti seluruh butir soal pada alat ukur ini dapat berfungsi dengan baik dalam mengukur opportunities for professional development. Contoh butir alat ukur ini adalah 'saya cukup dapat mengembangkan diri di klinik ini' dan 'saya mendapatkan kesempatan yang sama dengan rekan-rekan saya di klinik ini untuk mengembangkan diri'. Reliabilitas diukur dengan menggunakan Alpha's Cronbach dan diperoleh nilai 0.946 , artinya alat ukur opportunities for professional development ini tergolong reliabel.

Alat ukur yang digunakan untuk mengukur skills discretion adalah VET-DRQ pada sub bagian skills discretion yang dikembangkan oleh Mastenbroek et al. (2013b). Alat ukur ini diadaptasi ke dalam bahasa Indonesia dan ditambahkan beberapa butir soal. Hasilnya terdapat 8 butir soal dengan nilai outer loading di atas 0.6 . Hal ini berarti seluruh butir soal pada alat ukur ini dapat berfungsi baik dalam mengukur skills discretion. Contoh butir soal adalah 'pekerjaan saya .... memberikan kesempatan untuk melakukan pendekatan yang berbeda untuk setiap pasien.' dan 'pekerjaan saya ... memberikan kesempatan untuk menunjukkan kemampuan/keterampilan'. Reliabilitas diukur dengan menggunakan Alpha's Cronbach dan menghasilkan nilai sebesar 0.887. Hal ini berarti alat ukur skills discretion tergolong reliabel. 
Alat ukur yang digunakan untuk mengukur self efficacy adalah VET-DRQ pada sub bagian self efficacy yang dikembangkan oleh Mastenbroek et al. (2013b). Alat ukur ini diadaptasi ke dalam bahasa Indonesia, ditambahkan butir soal, dan diberikan penambahan konteks pekerjaan. Konteks pekerjaan penting untuk dimasukkan ke dalam butir soal karena self efficacy sendiri bersifat spesifik terhadap konteks pekerjaan (Bandura, 1997). Butir soal alat ukur ini pada awalnya berjumlah 17 butir yang kemudian menjadi 10 butir soal. 7 butir soal harus dieliminasi karena memiliki nilai outer loading di bawah 0.6. Contoh butir soal pada alat ukur ini adalah 'saya merasa ... dalam melakukan tindakan operasi' dan saya merasa ... dapat memenuhi ekspektasi klien'. Reliabilitas diukur dengan menggunakan Alpha's Cronbach dan menghasilkan nilai sebesar 0.913. Hal ini berarti alat ukur self efficacy tergolong reliabel.

Peneliti membuat kuesioner penelitian secara online dengan bantuan google form. Selanjutnya peneliti mengirimkan link kuesioner tersebut ke setiap dokter hewan di klinik hewan X secara personal. Pada saat itu pula peneliti menjelaskan tujuan penelitian dan memberikan pernyataan bahwa kerahasiaan identitas akan terjaga. Pengambilan data dilakukan dari tanggal 9 April 2018 hingga 18 Mei 2018.

\section{HASIL DAN PEMBAHASAN}

Tabel 1 menunjukkan nilai rata-rata (mean) dan simpangan baku (SD), dan korelasi dari setiap variabel penelitian. Tabel 1 juga menampilkan nilai tengah (median) dari setiap alat ukur. Berdasarkan perbandingan antara mean dan nilai tengah alat ukur, peneliti menggolongkan setiap variabel penelitian ke golongan rendah, sedang, dan tinggi. Tabel 2 menunjukkan perhitungan uji mediasi self efficacy sebagai mediator antara opportunities for professional development dan work engagement. Tabel 3 menunjukkan perhitungan uji mediasi self efficacy sebagai mediator antara skills discretion dan work engagement.

Tabel 1. Mean, standar deviasi (SD), median, dan korelasi antar variabel

\begin{tabular}{llcccccc}
\hline \multirow{2}{*}{ Variabel } & $\begin{array}{c}\text { Mean } \\
(\mathrm{SD})\end{array}$ & Median & 1 & 2 & 3 & 4 \\
\hline 1 & Work Engagement & 3.42 & 2.50 & $\mathbf{. 8 7 1}$ & & & \\
& & $(.365)$ & & & & & \\
2 & Opportunities for Professional Development & 3.28 & 2.50 & .384 & $\mathbf{. 9 4 6}$ & & \\
& & $(.615)$ & & & & & \\
3 & Skills Discretion & 3.44 & 2.50 & $.661^{* *}$ & $.519^{* *}$ & $\mathbf{. 8 8 7}$ & \\
& Self Efficacy & $(.429)$ & & & & & \\
& 2.77 & 2.50 & $.638^{* *}$ & .262 & $.504^{* *}$ & $\mathbf{. 9 1 3}$ \\
\hline
\end{tabular}

Keterangan: Angka yang dicetak tebal menunjukkan nilai Alpha's Cronbach atau reliabilitas dari setiap alat ukur. Korelasi dengan tanda $* *$ menandakan bahwa korelasi tersebut signifikan $(\mathrm{p}<0.01)$

Berdasarkan perbandingan antara nilai mean dan nilai median alat ukur, maka peneliti menggolongkan setiap variabel penelitian. Work engagement, opportunities for professional development, dan skills discretion pada responden penelitian tergolong tinggi karena memiliki nilai mean yang berada jauh di atas nilai median alat ukur. Di sisi lain, self efficacy responden penelitian tergolong sedang karena memiliki nilai mean sedikit di atas nilai median alat ukur. 
Tabel 2. Hasil uji self efficacy sebagai mediator antara OPD - WE

\begin{tabular}{lrrr}
\hline Tahapan Uji Mediasi & Nilai t & Nilai $\beta$ & Nilai p \\
\hline $\begin{array}{l}\text { Outcome 1: Work Engagement } \\
\text { Predictor 1: Opportunities for Professional Development }\end{array}$ &, 739 &, 384 &, 460 \\
$\begin{array}{l}\text { Outcome 2: Self efficacy } \\
\text { Predictor 2: Opportunities for Professional Development }\end{array}$ &, 634 &, 262 &, 527 \\
\hline Kent
\end{tabular}

Keterangan: $\mathrm{OPD}=$ Opportunities for Professional Development; WE $=$ Work Engagement; $\mathrm{t}=$ Nilai uji signifikansi $\mathrm{t} ; \beta=$ Koefisien regresi; $\mathrm{p}=$ Nilai uji signifikansi $\mathrm{p}$

Hipotesis pertama diuji dengan menggunakan aturan uji mediasi dari Baron dan Kenny (1986). Untuk itu perlu dilakukan uji regresi terlebih dahulu antar variabel yang berperan. Setelah dilakukan uji regresi ditemukan bahwa: (1) Peran opportunities for professional development terhadap self efficacy tidak signifikan, $\beta=.262, p>.05$; (2) Peran opportunities for professional development terhadap work engagement tidak signifikan $\beta=.384, p>.05$.

Berdasarkan uji regresi tersebut, dapat disimpulkan bahwa self efficacy tidak berperan sebagai mediator antara opportunities for professional development dan work engagement. Artinya, sebanyak apapun kesempatan mengembangkan profesi yang diperoleh dokter hewan kurang dapat meningkatkan keyakinan dirinya dalam bekerja sehingga work engagement tidak mengalami peningkatan. Hal ini kemungkinan terjadi karena sampel yang diambil adalah para dokter hewan yang banyak memeroleh kesempatan untuk mengikuti kursus di luar negeri. Ilmu kedokteran hewan di luar negeri berkembang jauh lebih pesat dibandingkan Indonesia sehingga ilmu yang telah dipelajari tersebut belum tentu dapat diterapkan di Indonesia. Akibatnya keyakinan diri para dokter hewan tidak bertambah dengan banyaknya kursus yang mereka ikuti di luar negeri.

Tabel 3. Hasil uji self efficacy sebagai mediator antara SD - WE

\begin{tabular}{lcccc}
\hline Tahapan Uji Mediasi & $\beta$ & STDEV & $\mathrm{p}$ & $\mathrm{t}$ \\
\hline $\begin{array}{l}\text { Pengujian Tahap 1 (Tanpa Mediator) } \\
\text { Outcome 1: Work Engagement }\end{array}$ & & & & \\
Predictor 1: Skills Discretion &, $661^{* *}$ &, 063 &, 000 & 10,535 \\
Outcome 2: Self Efficacy & & & & \\
Predictor 2: Skills Discretion &, $504^{* *}$ &, 167 &, 003 & 3,022 \\
Outcome 3: Work Engagement & & & & \\
Predictor 3: Self Efficacy &, $638^{* *}$ &, 139 &, 000 & 4,580 \\
Pengujian Tahap 2 (Dengan Mediator) & & & & \\
Outcome: Work Engagement & & & & \\
Predictor: Skills Discretion &, $497^{* *}$ &, 146 &, 001 & 3,407 \\
Mediator: Self Efficacy &, $360^{*}$ &, 148 &, 016 & 2,426 \\
\hline
\end{tabular}

Keterangan: $\mathrm{SD}=$ Skills Discretion; WE $=$ Work Engagement; $\beta=$ koefisien regresi; STDEV= Standar Deviasi; $\mathrm{p}=$ Nilai uji signifikansi $\mathrm{p}$; $=$ Nilai uji signifikansi t. Tanda * menandakan bahwa korelasi tersebut signifikan $(\mathrm{p}<0.05), * *$ menandakan bahwa korelasi tersebut signifikan $(\mathrm{p}<0.01)$ 
Hipotesis kedua diuji dengan menggunakan aturan uji mediasi dari Baron dan Kenny (1986). Uji regresi dilakukan terlebih dahulu dan ditemukan bahwa: (1) Peran skills discretion terhadap work engagement signifikan, $\beta=.661, p<.01$; (2) Peran skills discretion terhadap self efficacy signifikan, $\beta=.504, p<.01$; (3) Peran self efficacy terhadap work engagement signifikan, $\beta=$ $.638, p<.01$.

Selanjutnya dilakukan Sobel Test dan terbukti bahwa self efficacy berperan sebagai mediator antara skills discretion dan work engagement $(z=2.021, p<.05)$. Di sisi lain, peran mediator ini bersifat parsial karena terjadi penurunan koefisien regresi apabila mediator berperan.

Hasil ini sejalan dengan penelitian lainnya yang menjelaskan bahwa self efficacy dapat berperan sebagai mediator parsial antara job resources dan work engagement (Mastenbroek et al., 2012; Xanthopoulou et al., 2007). Hal ini menunjukkan bahwa job resources berupa skills discretion juga dapat berperan meningkatkan self efficacy dan kemudian meningkatkan work engagement seseorang. Artinya, apabila para dokter hewan memiliki kesempatan untuk menerapkan keterampilan-keterampilan yang dimilikinya ke dalam pekerjaannya, maka keyakinan dirinya dalam bekerja akan meningkat sehingga kemudian work engagement yang dimilikinya akan meningkat.

\section{KESIMPULAN DAN SARAN}

Melalui penelitian ini dapat disimpulkan bahwa self efficacy berperan sebagai mediator parsial dalam menjelaskan hubungan antara skills discretion dan work engagement. Mediator parsial berarti hanya sebagian saja hubungan antara skills discretion dan work engagement yang dapat dijelaskan oleh self efficacy.

Bila dibandingkan dengan penelitian sebelumnya, perbedaan yang menonjol adalah bahwa self efficacy tidak berperan sebagai mediator antara opportunities for professional development dan work engagement. Perbedaan ini kemungkinan disebabkan oleh perbedaan konteks tempat penelitian, di mana penelitian terdahulu dilakukan di Belanda dan sekarang dilakukan di Indonesia. Dalam konteks di Indonesia, opportunities for professional development digambarkan dengan banyaknya kesempatan bagi para dokter hewan untuk mengikuti kursus di berbagai tempat dan dalam hal ini mayoritas dokter memilih untuk mengikuti kursus di luar negeri. Di sisi lain ilmu kedokteran hewan di luar negeri mayoritas jauh lebih berkembang dibandingkan di Indonesia sehingga hal yang mereka peroleh di luar negeri kebanyakkan tidak dapat diterapkan di Indonesia sehingga self efficacy terhadap pekerjaan mereka pada akhirnya tidak meningkat.

Untuk saran praktis, peneliti merekomendasikan kepada manajemen Klinik hewan $\mathrm{X}$ agar memberikan lebih banyak kesempatan pada dokter hewannya untuk mempergunakan keterampilan yang dimilikinya secara nyata. Sebagai contoh, dokter hewan dapat diberikan kesempatan untuk latihan praktik kepada kucing-kucing atau hewan liar lainnya yang berkeliaran untuk latihan steril dan sebagainya. Harapannya adalah agar dokter hewan memiliki pengalaman memepergunakan keterampilan yang dimilikinya secara nyata sehingga keyakinan dirinya dalam bekerja dapat meningkat. Selain itu, peneliti juga menyarankan agar setiap dokter hewan diberikan kesempatan untuk menangani komplain kliennya secara langsung dan tidak merujuk kepada dokter hewan senior untuk membantu menangani komplain klien. Apabila dokter hewan menangani komplainnya secara langsung diharapkan ke depannya ia akan semakin percaya diri dalam menghadapi klien dengan tuntutan yang tinggi. 


\section{Ucapan Terima Kasih (Acknowledgement)}

Peneliti mengucapkan terima kasih kepada klinik hewan X, pendiri klinik, dan juga segenap staf dan dokter hewan yang bekerja di klinik tersebut. Terima kasih juga diberikan kepada ketua asosiasi dokter hewan praktisi hewan kecil yang telah memberikan data awal yang menunjang peneliti untuk menyusun latar belakang penelitian ini. Peneliti juga mengucapkan terima kasih kepada seorang dokter hewan yang telah berpengalaman bekerja selama 35 tahun di bidang hewan peliharaan yang telah memberikan gambaran mengenai kondisi dan tantangan yang dihadapi oleh dokter hewan praktisi hewan kecil di Indonesia.

\section{REFERENSI}

Bakker, A. B., Demerouti, E., \& Verbeke, W. (2004). Using the job demands-resources model to predict burnout and performance. Human Resource Management, 43, 83-104. doi: $10.1002 / \mathrm{hrm}$

Bakker, A. B. (2011). An evidence-based model of work engagement. Current Directions in Psychological Science, 20, 265-269. doi: 10.1177/0963721411414534

Bandura, A. (1997). The exercise of control. WH Freeman and Company.

Christian, M. S., Garza, A. S., \& Slaughter, J. E. (2011). Work engagement: a quantitative review and test of its relations with task and contextual performance. Personnel Psychology, http://www.researchgate.net/publication/211384078_Work_Engagement_A_Quantitative _Review_and_Test_of_Its_Relations_with_Task_and_Contextual_Performance

Byrne, Z. S., Peters, J. M., \& Weston, J. W. (2016). The struggle with employee engagement: measures and construct clarification using five samples. Journal of Applied Psychology, 101, 1201-1227. doi: 10.1037/ap10000124

Franedya, R. (2009, Maret 13). Penyedia aksesori dan peralatan hewan peliharaan. Kompas. http://travel.kompas.com

Lorente, L., Salanova, M., Martinez, I. M., Vera, M. (2014). How personal resources predict work engagement and self-rated performance among construction workers: A social cognitive perspective. International Journal of Psychology, 49(3), 200-207. http://repositori.uji.es/xmlui/handle/10234/134965

Mastenbroek, N. J. J. M., Jaarsma, A. D. C., Scherpbier, A. J. J. A., van Beukelen, P., Demerouti, E. (2012). The role of personal resources in explaining well-being and performance: a study among young veterinary professionals. European Journal of Work and Organizational Psychology, 1-13. doi: 10.1080/1359432X.2012.728040

Mastenbroek, N. J. J. M., Jaarsma, A. D. C., Demerouti, E., Muijtjens, A. M. M., Scherpbier, A. J. J. A., \& van Beukelen, P. (2013a). Burnout and engagement, and its predictors in young veterinary professionals: the influence of gender. Veterinary Record. doi: $10.1136 / v r .101762$

Mastenbroek, N. J. J. M., Demerouti, E., van Beukelen, P., Muijtjens, A. M. M., Scherpbier, A. J. J. A., \& Jaarsma, A. D. C. (2013b). Measuring potential predictors of burnout and engagement among young veterinary professionals; construction of a customised questionnaire (the Vet-DRQ). Veterinary Record. doi: 10.1136/vr.101761

Sukarelawati, E. (2017, Maret 13). Praktisi memelihara hewan mewah tren baru gaya hidup. Antaranews. http://jatim.antaranews.com

Schaufeli, W. B. \& Bakker, A.B. (2004). Job demands, job resources, and their relationship with burnout and engagement: a multi-sample study. Journal of Organizational Behavior, 25, 293-315. doi: 10.1002/job.248 
Schaufeli, W. B., Bakker, A. B., \& Salanova, M. (2006). The measurement of work engagement with a short questionnaire: a cross-national study. Educational and Psychological Measurement, 66, 701-716. doi: 10.1177/0013164405282471

Surjanata, A., Prodjodihardjo, S., Poedjomartono, S., Sitepoe, M., Pronohartono, T., Moerad, B., Setiabudi, P., Bagja, W., Sudibyo, L. A., Widharetna, T., Utomo, D. B., Purnomo, F. N., Pudjiono, S., Hartono, Ernita, R. (2010). 100 tahun dokter hewan Indonesia, sejarah, kiprah, dan tantangan. Yayasan Hemerazoa.

Viotti, S. \& Converso, D. (2016). Relationship between job demands and psychological outcomes among nurses: does skill discretion matter?. International Journal of Occupational Medicine and Environmental Health, 29, 439-460. doi: 10.13075/ijomeh.1896.00520

Xanthopoulou, D., Bakker, A. B., Demerouti, E., \& Schaufeli, W. B. (2007). The role of personal resources in the job demands-resources model. International Journal of Stress Management, 14, 121-141. doi: 10.1037/1072-5245.14.2.121

Xanthopoulou, D., Bakker, A. B., Demerouti, E., \& Schaufeli, W. B. (2009). Reciprocal relationships between job resources, personal resources, and work engagement. Journal of Vocational Behavior, 74, 235-244. doi: 10.1016/j.jvb.2008.11.003 